\title{
O novo plano de direitos humanos e a questão do trabalho no Brasil
}

César Augusto Ribeiro Nunes Mestrando em Sociologia pela Universidade de Coimbra, Portugal

\section{Resumo}

Pesquisa acerca das mudanças das relações de trabalho no cenário mundial da economia neoliberal atual, marcada pelos passos e descompassos entre a matriz legal advinda da Direito do Trabalho (surgido no início da industrialização) e a flexibilização dos direitos laborais da atualidade. Pretende-se, a partir da compreensão da denominada "crise do trabalho", definir argumentos que permitam responder a questão central: qual o futuro das relações de trabalho e, principalmente, do direito do trabalho nas sociedades modernas. Na seqüência, reflete-se sobre o Novo Plano Nacional de Direitos Humanos do Brasil PNDH-3, sua importância para a defesa dos direitos humanos dos trabalhadores e para a conquista do trabalho decente.

Palavras-chave: Direitos Humanos; Trabalho.

\begin{abstract}
Research on the changing labor relations in the global scenario of current neoliberal economy, marked by steps and gaps between the matrix arising from the Legal Right to Work (emerged at the beginning of industrialization) and flexibility of labor rights today. It is intended, from the understanding of socalled "crisis of work", set arguments for addressing the central question: what is the future of labor relations, and especially of labor law in modern societies. Subsequently, reflects on the New National Plan for Human Rights of Brazil PNDH-3, its importance to the human rights of workers and for the achievement of decent work.
\end{abstract}

Key-words: Human Rights; Labor. 


\section{Introdução}

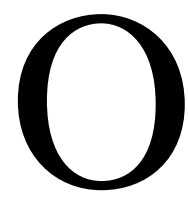

presente artigo situa-se no campo temático das relações teóricas entre Direitos Laborais e Direitos Humanos, uma articulação especial na

abrangente configuração reflexiva e metodológica dos Direitos Econômicos, Sociais e Culturais. Importante ressaltar, de antemão, que a presente proposta de articulação entre estes temas constitui-se uma realidade recente do Brasil, o que pode ser evidenciado através de uma pequena recuperação histórica. Seguramente, um destacado número de normas jurídicas, bem como um significativo acúmulo de pesquisas e levantamentos já se formaram acerca do tema dos Direitos Laborais em nosso país, conforme se observa, por exemplo, no acúmulo temporal resultado do surgimento dessa matéria como esfera institucional de atuação do Estado, tendo em vista a criação das primeiras normas de regulação das relações de trabalho na década de 1920. Naquele momento o sistema de produção nacional sofria uma radical mudança por iniciativa do Estado, de modo que ocorre a transferência do capital produtivo do setor agrário-exportador para a estrutura em formação de natureza urbano-industrial. No cenário político, esse momento também corresponde a conjuntura social que culminou com a Revolução burguesa de 1930 e a chegada ao poder do Presidente Getúlio Vargas (PRADO JÚNIOR, 1945; FURTADO, 2007).

Em 1943, por exemplo, foi promulgado por Vargas o Decreto-Lei $\mathrm{n}^{\circ}$ 5.452, denominado de Consolidação das Leis do Trabalho - CLT, documento normativo de base legal mais importante do Direito Laboral brasileiro até os tempos atuais. Em apertada síntese, somam-se, portanto, mais de 80 anos de produções teóricas, fatos históricos, lutas sociais, discussões políticas e medidas econômicas relacionadas ao Direito do Trabalho no Brasil. Por consequência, este significativo período de história também revela a significativa experiência prática da sociedade brasileira 
com questões pertencentes ao Direito do Trabalho, fato este que pode ser observado pela existência de um elevado número de pesquisas e estudos de Direito do Trabalho, ao mesmo nível em que se encontra a produção teórica de disciplinas mais tradicionais de Direito como Civil, Penal, Constitucional e etc.

Não obstante, não podemos tecer a mesma consideração histórica da qual nos referimos sobre o Direito do Trabalho para tratar dos Direitos Humanos, igualmente considerados em seu aspecto institucional e jurídico. Como sabemos, este tema foi recentemente incluído na tradição jurídica brasileira, pois de fato os Direitos Humanos nunca fizeram parte da experiência política, jurídica e social brasileira. Ademais, como exemplo desse distanciamento evidenciado entre Estado, sociedade civil e o tema dos Direitos Humanos identificamos que há pouco tempo as Universidades e faculdades brasileiras passaram a incluir este tema no rol das disciplinas obrigatórias da grade curricular dos cursos de Direito. Em termos numéricos, por sua vez, é fato que um em cada quatro municípios do Brasil possui estrutura específica para gestão de direitos humanos, segundo o registro da Pesquisa de Informações Básicas Municipais (Munic. 2009), divulgada em 10 de maio de 2010 pelo Instituto Brasileiro de Geografia e Estatística - IBGE.

Em verdade, esta constatação não significa reconhecer que o Brasil desconhece ou nunca testemunhou ações, propostas ou fatos sociais que se relacionassem aos Direitos Humanos. O que queremos salientar, em contrapartida, é que nunca os Direitos Humanos foram abordados no Brasil de forma profunda, integrada, metodológica e ampla. Coaduna para nossa tese o fato do Brasil ter reconhecido apenas na Constituição de 1988 os direitos e garantias fundamentais do homem e do cidadão, ato que marca a história do país na busca de solidificar os ideais de justiça e democracia, depois de viver sob uma ditadura militar de mais de duas décadas.

O Brasil, sob esse ponto de vista, possui uma história de lutas sociais e de desenvolvimento político-jurídico de caráter peculiar, na qual as 
reivindicações sempre puderam ser identificadas em questões e "bandeiras” específicas. São exemplos as lutas pela Democracia, durante o período Militar (1964-1985), as lutas sindicais de trabalhadores durante o Governo de Getúlio Vargas (1930-1945), e mais recentemente os movimentos de defesa dos direitos das crianças, dos idosos e das mulheres, por exemplo, que culminaram, respectivamente, com a promulgação dos Estatutos da Criança e do Adolescente, dos Idosos e da Lei denominada "Maria da Penha”, em defesa dos direitos das mulheres.

A última década, entretanto, trouxe novos contextos sociais no que tange aos Direitos Humanos no Brasil. A despeito da importância dos temas Direito Laboral e Direitos Humanos, uma das mais novas iniciativas ocorridas no Brasil foi a criação do Programa Nacional de Direitos Humanos - PNDH-3, lançado no final do ano de 2009. O referido Plano marca a solidificação de um criterioso e representativo movimento social para defesa e proteção dos Direitos da pessoa humana. Abrangente no que diz respeito aos temas abordados e inédito no que diz respeito ao desenvolvimento de uma política nacional para defesa dos Direitos Humanos, nosso país atingiu nos últimos anos o nível mais elevado e qualitativo sobre o tema.

Em referência aos Direitos Humanos e às relações de trabalho, no novo plano foram elencadas 14 ações para a busca de um trabalho decente no Brasil, que serão citados na sequência desse artigo. Cabe a nós, nesse momento, refletir sobre as seguintes questões: Podemos extrair dessas ações programáticas aquilo que se entende por concepção decente e democrática do trabalho? Ainda: Até que ponto esse novo plano de Direitos Humanos contribui para a busca de um trabalho decente e para a criação de um direito laboral igualmente democrático? E por último: Podemos afirmar que o Plano de Direitos Humanos brasileiro está em consonância com as conjunturas sociais, econômicas e políticas da sociedade capitalista globalizada, da qual se revela atualmente uma transformação nas relações e no Direito do Trabalho? 
Importante relacionarmos os questionamentos que propomos com as orientações iniciais de Casimiro Ferreira (FERREIRA, 2002, p. 257), quando este discorre, ainda que genericamente, sobre a necessidade de se formar uma concepção decente e democrática do trabalho e de seus direitos. Diz o autor: "As noções de trabalho, relações laborais, de direito do trabalho e as realidades sociais, políticas, econômicas e culturais que lhe subjazem atravessam um período de profundas transformações”. Casimiro Ferreira, assim como muitos outros autores da área de economia, sociologia e direito, defendem que a sociedade moderna vive hoje a chamada crise do trabalho, ou seja, presenciamos hoje uma alteração do paradigma clássico do trabalho e, por conseqüência, do direito do trabalho. Tais alterações atingem, sem sombra de dúvidas, diretamente os direitos trabalhistas da classe operária, tanto que a legislação correspondente tem mostrado nos últimos anos características até então inimagináveis, ou seja, as tendências desregulamentadoras e flexibilizadoras do direito laboral. Em outras palavras, direitos conquistados com muita militância e intensa luta pela classe trabalhadora estão sendo eliminados do ordenamento jurídico brasileiro (ANTUNES, 2007).

É precisamente na intenção de responder os questionamentos acima citados, bem como formular uma resposta política aos prejuízos causados pela crise do trabalho que empreendemos a presente pesquisa. Como estudantes e pesquisadores não temos dúvida que qualquer estudo inicial sobre os direitos humanos passa por uma introdutória dificuldade de definir o que são os Direitos Humanos. O autor Ingo Wolfgang Sarlet escreve sobre o tema na medida em que distingue os termos "direitos dos homens", “direitos humanos” e "direitos fundamentais". Na visão do doutrinador os denominados direitos dos homens revelam uma análise a partir do referencial filosófico jusnaturalista, enquanto os direitos humanos seriam produtos dos referenciais filosóficos positivistas. Por último, os direitos fundamentais constituiriam o rol de direitos reconhecidos e protegidos pelo direito constitucional de cada dos novos Estados - Constitucionais (SARLET, 2001). 
Por esta leitura, direitos humanos corresponderiam ao rol de direitos inerentes à condição humana, mas que também são protegidos internacionalmente. Outro autor referencial para nós sobre o tema, J. J. Gomes Canotilho (CANOTILHO, 2003, p. 393), defende que, mesmo parecendo sinônimas, as expressões “direitos do homem” e "direitos fundamentais” guardam diferenças quanto a origem, ou seja, enquanto: “direitos do homem são direitos válidos para todos os povos e em todos os tempos (dimensão jusnaturalista-universalista), direitos fundamentais são os direitos do homem, jurídico-institucionalmente garantidos e limitados espácio-temporalmente”.

Em vista dessas considerações introdutórias formulamos, com apoio nos autores apresentados, a premissa de que os direitos humanos são, portanto, os direitos naturais da pessoa humana, de características invioláveis, intertemporais e universais. Foi esta, inclusive, a orientação filosófica de Direito Natural que caracterizou os escritos sobre o tema no transcorrer das Idades Antiga e Média até lograrmos atingir o tempo que convencionamos chamar de Modernidade. Neste último momento, entretanto, descobrimos que os direitos humanos encontram-se relacionado aos ideais burgueses inspiradores das revoluções francesa (1789) e americana (1776), tanto que ambas produziram os primeiros marcos legais da história dos direitos humanos com maior ressonância social: a Declaração dos Direitos do Homem e do Cidadão (1789) e o "Bill of Rights” (1791), respectivamente.

Outra dificuldade que observamos no estudo inicial de direitos humanos corresponde à ardilosa tarefa de definir quais seriam, por fim, os preclaros e genuínos direitos humanos. O jurista tcheco-francês Karel Vasak, em 1979, inspirado nos ideais da Revolução francesa, foi o primeiro a propor uma tipologia ou divisão entre gerações dos Direitos Humanos. Para cada geração que reconheceu o jurista remete um lema do ideal burguês, restando dessa forma estabelecido: Primeira Geração são dos Direitos Civis e Políticos (Liberdade); Segunda Geração são os Direitos Econômicos, Sociais e Culturais (Igualdade) e Terceira Geração são os 
Direitos Ambientais, do Consumo, dos Grupos Sociais e das Minorias (Fraternidade).

O auxílio dessa divisão nos facilita realizar uma leitura seqüencial de acontecimentos históricos, nomeadamente no que diz respeito aos marcos jurídicos e criação dos mecanismos de proteção correspondentes dos Direitos Econômicos, Sociais e Culturais, conforme apresentado anteriormente. Em seqüência, relembramos que o marco referencial dos direitos de segunda geração situa-se no ano de 1918, com a criação da Constituição alemã de Weimar (1919). Dizemos isto pelo fato desta constituição ser fruto de um movimento constitucionalista que buscava alcançar o Estado Social, em contraposição ao que se observava em matéria de direitos humanos até o momento (direitos de primeira geração). Naquele momento, alterava-se a perspectiva dos direitos humanos que dominava o pensamento até aquele momento, na qual se priorizava a defesa do indivíduo contra o Estado absolutista sob a bandeira do direito à vida e às liberdades de expressão, religião, de movimento e de residência.

Conforme apresentado os Direitos Econômicos, Sociais e Culturais marcam uma ruptura com relação ao tema dos Direitos Humanos, uma vez que estes são debatidos e exigidos no contexto das revoluções liberais, enquanto aqueles representam interesses de sociedades que clamam pelo Estado-Social ou pelo “welfare state”. Com fortes influências de teorias socialistas e social-democratas que marcam a primeira metade do século XX, o novo modelo de Direitos Humanos foi mais tarde aplicado na edição da Constituição espanhola (1931) e da Carta Magna brasileira de 1934, conforme nos revela os apontamentos históricos de Ferreira Filho (FERREIRA FILHO, 2008).

Observa-se, pela nova orientação, que os Direitos de Segunda Geração pretendem alargar o rol de direitos inerentes à condição humana, na medida em que acrescenta os chamados direitos positivos. Enumeram-se estes novos direitos sociais como subjetivos que permitem ao sujeito ativo (pessoa humana) exigi-los da pessoa passiva (Estado), e ainda, obriga este a 
ser responsável pela satisfação de tais direitos. Em resumo, credita-se pela nova doutrina de Direitos Humanos que todo homem tem direito à justiça social, à segurança social, ao trabalho, à educação, à proteção social e à habitação, entre outros. Ao Estado, como contraprestação, cabe prestar o serviço com objetivo de satisfazer sua obrigação.

$\mathrm{Na}$ consideração da origem do reconhecimento dos direitos trabalhistas, a data de 1919 é igualmente significativa, pois foi nesse mesmo ano que se originou a maior organização internacional relacionado ao trabalho do mundo, denominada Organização Internacional do Trabalho OIT. Hoje esse órgão faz parte da Organização das Nações Unidas - ONU e tem por finalidade promover a justiça social no que tange ao direito do trabalho dentro dos Estados a ele vinculado. O objetivo maior de criação desse órgão foi o de garantir os direitos humanos dos trabalhadores, tendo em vista, por exemplo, o processo de exploração das condições de trabalho que se evidenciou com a Revolução Industrial. A atuação deste importante órgão internacional tem sido no sentido de pactuar direitos mínimos a serem salvaguardados pelos países signatários, tanto que no ano de 1998 foi adotada pela OIT a Declaração sobre os Princípios e Direitos Fundamentais no Trabalho e seu Seguimento. Nesta Declaração, restaram como objetivos dos Estados signatários a eliminação de todas as formas de trabalho forçado, a abolição efetiva do trabalho infantil, a eliminação da discriminação em matéria de emprego e ocupação e a liberdade de associação e liberdade sindical.

Não obstante, a defesa do Direito ao Trabalho não fez parte somente de ações promovidas pela OIT, a própria ONU, no ano de 1966, já havia consagrado o direito ao trabalho no Pacto Internacional de Direitos Econômicos, Sociais e Culturais, na medida em que considera este como meio de garantir a vida. O referido pacto, no entanto, traz mais direitos sociais em seu texto, razão pela qual dedicamos nossa análise dos direitos trabalhistas apenas no que diz respeito às ações da OIT. Dessa forma, destacamos a Conferência Internacional do Trabalho, realizada pela OIT todo ano, no mês de junho, na cidade de Genebra (Suíça), como o maior 
fórum de debate sobre as questões do trabalho da atualidade. Nessas reuniões, além de debates entre os membros sobre as mais diversas questões do mundo do trabalho, são revisadas e adotadas normas internacionais, bem como são elaborados programas para a busca da melhoria nas condições laborais em todos os países.

Em uma dessas reuniões da Conferência Internacional do Trabalho, realizada no ano de 1999, ficou estabelecido como meta da OIT a busca por um trabalho decente, conceito que busca a convergência de quatro fatores: promoção dos direitos fundamentais do trabalho; o emprego; a proteção social e o diálogo social. Em resumo, conforme se desprende do sítio eletrônico da OIT, o trabalho definido como decente ${ }^{1}$ :

(...) puede ser sintetizado en cuatro objetivos estratégicos: principios y derechos fundamentales en el trabajo y normas laborales internacionales; oportunidades de empleo e ingresos; protección y seguridad social; y diálogo social y tripartismo. Estos objetivos tienen validez para todos los trabajadores, mujeres y hombres, en la economía formal e informal, en trabajos asalariados o autónomos; en el campo, industria y oficina; en sus casas o en la comunidad.

El trabajo decente es fundamental en el esfuerzo por reducir la pobreza, y es un medio para lograr un desarrollo equitativo, inclusivo y sostenible. La OIT trabaja en el desarrollo de enfoques orientados hacia el Trabajo Decente en las políticas sociales y económicas, en colaboración con las principales instituciones y representantes del sistema multilateral y la economía global.

Sem dúvidas, acreditamos ser essa nova concepção de trabalho a mais debatida nos dias atuais. De igual forma, acreditamos serem os programas desenvolvidos pela OIT para busca e conquista de um trabalho decente as ações internacionais de maior benefício para os trabalhadores em escala global. Dizemos isto no momento em que observamos uma referência do tema trabalho decente ter sido posto como objetivo estratégico do novo Plano de Direitos Humanos do Brasil, aprovado em 21 de dezembro de 2009, com a assinatura do Decreto n 7.037 pelo Presidente da República

1 cf. “Trabajo decente para todos”. Texto on-line. Disponível em: http://www;ilo.org/global/About_the_ILO/Mainpillars/WhatisDecentWork/lang_es/index.htm. Acessado em junho de 2010. 
Luiz Inácio Lula da Silva. O Programa Nacional de Direitos Humanos do Brasil - PNDH-3, em consonância com as diretrizes, objetivos estratégicos e ações programáticas estabelecidas no próprio texto. Na sua organização geral, o PNDH-3 foi dividido em seis diferentes eixos orientadores, dessa forma nomeados: I - Interação democrática entre Estado e sociedade civil; II - Desenvolvimento e Direitos Humanos; III - Universalizar direitos em um contexto de desigualdades; IV - Segurança Pública, Acesso à Justiça e Combate à Violência; V - Educação e Cultura em Direitos Humanos; e VI Direito à Memória e à Verdade.

De imediato, a partir de uma análise conjuntural, podemos afirmar com segurança que a aprovação desse Plano corresponde ao mais recente passo da sociedade civil organizada brasileira para o fortalecimento da democracia plena de direitos que se almeja alcançar, marcadamente após a promulgação da Constituição Federal de 1988 (art. 102). Cumpre destacar que o Brasil, entretanto, no que tange à criação de um órgão estatal próprio para a defesa ampla dos Direitos Humanos, somente começou a institucionalizar os fundamentos constitucionais previstos nos artigos iniciais da Carta Maior ou, em outras palavras, os fundamentos do Estado Democrático de Direito, nos anos de 1996/1997, com a criação, respectivamente, do Plano Nacional de Direitos Humanos - PNDH e da Secretaria Nacional de Direitos Humanos - SNDH. Naquele momento, criou-se a Secretaria em destaque na estrutura organizacional do Ministério da Justiça, em substituição ao que se denominava Secretaria dos Direitos da Cidadania. Em 1999, entretanto, a SNDH foi transformada em Secretaria de Estado dos Direitos Humanos - SEDH, porém tal mudança de nomenclatura não representou grandes avanços administrativos, uma vez que o órgão

\footnotetext{
${ }^{2}$ Diz o art. $1^{\circ}$ da Constituição Federal brasileira: “A República Federativa do Brasil, formada pela união indissolúvel dos Estados e Municípios e do Distrito Federal, constituise em Estado Democrático de Direito e tem como fundamentos: I - a soberania; II - a cidadania; III - a dignidade da pessoa humana; IV - os valores sociais do trabalho e da livre iniciativa; V - o pluralismo político":

cf. BRASIL. Constituição da República Federativa do Brasil de 1988. Texto on-line. Disponível em: http://www.planalto.gov.br/ccivil_03/constituicao/constitui\%C3\%A7ao.htm. Acesso em março de 2010.
} 
recebeu apenas assento nas reuniões ministeriais. Apenas no ano de 2003, ou seja, 15 anos depois de promulgada a Constituição, é que o Estado brasileiro elevou a estrutura da SEDH ao nível ministerial para criar a Secretaria Especial dos Direitos Humanos, órgão hoje ligado à Presidência da República, com competência para assessorar direta e imediatamente o Presidente da República na formulação de políticas e diretrizes voltadas à promoção dos direitos da cidadania da criança, do adolescente, do idoso e das minorias e desenvolver práticas voltadas à defesa dos direitos das pessoas com deficiência e promoção da sua integração à vida comunitária, bem como coordenar a política nacional de direitos humanos, em conformidade com as diretrizes do Programa Nacional de Direitos Humanos - PNDH, entre outras tarefas ${ }^{3}$.

Hoje, por conseqüência, reconhece-se que o Brasil avança no tema e na solidificação de espaços governamentais e não-governamentais de defesa dos Direitos Humanos, ao passo que podemos presenciar a existência até mesmo de ações integradas entre a política governamental e a atuação da sociedade civil organizada para defesa desses direitos. Em resumo, o PNDH-3 não só corresponde a uma ação do Governo brasileiro, tendo em vista a incorporação de elementos trazidos pelos tratados internacionais recentemente assinados (ONU e OEA), como também revela uma incorporação das resoluções aprovadas pela sociedade no transcorrer da $11^{\text {a }}$ Conferência Nacional de Direitos Humanos, realizada no ano de 2008 na Capital Federal.

Um ponto específico, entretanto, desse novo plano de Direitos Humanos merece uma análise criteriosa de nossa parte. Inserido no eixo orientador número III (Universalizar Direitos em um Contexto de Desigualdades) a diretriz de número 7 recebeu o nome de Garantia dos Direitos Humanos de forma universal, indivisível e independente, assegurando a cidadania plena. Ainda dentro desta diretriz, um dos objetivos estratégicos (de número VI) prescreve a garantia do trabalho decente,

\footnotetext{
${ }^{3}$ Cf. Art. 24, Lei $n^{\circ}$. 10.683, de 28 de Maio de 2003, com redação dada pela Medida Provisória no 483/2010.
} 
adequadamente remunerado, exercido em condições de equidade e segurança. Por fim, este objetivo estratégico revela quais são 14 ações programáticas do Plano de Direitos Humanos brasileiro para a questão do trabalho e do trabalhador na sociedade, são elas:

a) Apoiar a agenda nacional de trabalho decente por meio do fortalecimento do seu comitê executivo e da efetivação de suas ações;

b) Fortalecer programas de geração de empregos, ampliando progressivamente o nível de ocupação e priorizando a população de baixa renda e os estados com elevados índices de emigração;

c) Ampliar programas de economia solidária, mediante políticas integradas, como alternativo de geração de trabalho e renda, e de inclusão social, priorizando os jovens das famílias beneficiárias do Programa Bolsa Família;

d) Criar programas de formação, qualificação e inserção profissional e de geração de emprego e renda para jovens, população em situação de rua e população de baixa renda;

e) Integrar as ações de qualificação profissional às atividades produtivas executadas com recursos públicos, como forma de garantir a inserção no mercado de trabalho.

f) Criar programas de formação e qualificação profissional para pescadores artesanais, industriais e agricultores familiares;

g) Combater as desigualdades salariais baseadas em diferenças de gênero, raça, etnia e das pessoas com deficiência;

h) Acompanhar a implementação do Programa Nacional de Ações Afirmativas, instituído pelo Decreto $n^{\circ} 4.228 / 2002$, no âmbito da administração pública federal, direta e indireta, com vistas à realização e metas percentuais da ocupação de cargos comissionados pelas mulheres, populações negras e pessoas com deficiência;

i) Realizar campanhas envolvendo a sociedade civil organizada sobre a paternidade responsável, bem como ampliar a licença paternidade, como forma de contribuir para a corresponsabilidade e para o combate ao preconceito quanto à inserção das mulheres no mercado de trabalho;

j) Elaborar diagnósticos com base em ações judiciais que envolvam atos de assédio moral, sexual e psicológico, com apuração de denuncias de desrespeito aos direitos das 
trabalhadoras e trabalhadores, visando orientar ações de combate à discriminação e abuso nas relações de trabalho;

k) Garantira a igualdade de direitos das trabalhadoras e dos trabalhadores domésticos com os dos demais trabalhadores;

l) Promover incentivos as empresas para que empreguem os egressos do sistema penitenciário;

m) Criar cadastro nacional e relatório anual de empregabilidade de egressos do sistema penitenciário; e,

n) Garantir os direitos trabalhistas e previdenciários de profissionais do sexo por meio da regulamentação de sua profissão.

Para compreendermos, entretanto, o alcance e as possibilidades que se extraem das ações programáticas acima referidas necessitamos esclarecer, para além da conquista jurídico-institucional que representa, a caracterização de como se dão as relações trabalhistas no cenário capitalista que ainda vivenciamos, de modo que seja possível formarmos argumentos sólidos para responder ao questionamento central deste artigo, qual seja: como garantir a defesa dos direitos humanos dos trabalhadores brasileiros, tendo em vista a formação de uma nova ordem econômica?.

Sobre o cenário capitalista atual, destacamos o fenômeno da globalização como ponto de partida para compreensão das novas relações de trabalho. Além das caracterizações realizadas desse movimento pela mídia em busca da criação de um senso comum, no qual se destacam a liberalização do comércio internacional com a abertura das fronteiras para a entrada de produtos e serviços, políticas econômicas específicas que pretendem o controle inflacionário, bem como organização política baseada na democracia representativa liberal (PEREIRA, 2001), apoiamos nossa compreensão sobre o tema nas considerações de Boaventura de Sousa Santos (SANTOS, 2001, p. 33): quando destaca a existência das chamadas "globalizações":

A globalização, longe de ser consensual, é [...] um vasto e intenso campo de conflitos entre grupos sociais, Estados e interesses hegemônicos, por um lado, e grupos sociais, Estados 
e interesses subalternos, por outro; e mesmo no interior do campo hegemônico há divisões mais ou menos significativas.

Para Santos (SANTOS, 2001) são dois os grandes movimentos de globalização, o primeiro denominado "globalização hegemônica” e o segundo "globalização contra hegemônica”. Aquela é reproduzida pelas empresas transnacionais, pelos organismos financeiros internacionais e pelos capitalistas dos países centrais, enquanto esta pode ser percebida nas ações dos movimentos sociais e ONG's progressistas articuladas ao Fórum Social Mundial. Pereira (PEREIRA, 2007, p. 67) faz a leitura do texto de Boaventura de Sousa Santos no sentido de que:

(...) é possível dizer que a globalização tal como vem sendo desenhada e implementada pelo neoliberalismo hegemônico é uma, entre as variadas possibilidades abertas com as mudanças tecnológicas. É aquela orquestrada pelas empresas transnacionais e pelos governos dos países centrais, onde se localizam as matrizes dessas transnacionais, com o objetivo de ampliar sua capacidade de lucro e de domínio.

No Brasil os impactos da globalização neoliberal foram evidentes somente nos anos de 1994 a 2002, a partir da eleição do presidente Fernando Henrique Cardoso. FHC, como representante de um partido tido como de centro-direita no Brasil (Partido da Social Democracia Brasileira PSDB), foi o personagem que marcou a história do país como aquele que implementou a política neoliberal e que afastou o Estado das relações econômicas. O novo Presidente da República foi responsável por integrar, subservientemente, a economia e os interesses do Brasil às diretrizes elaboradas pelo Consenso de Washington, realizado no ano de 1989, por economistas de instituições baseadas na capital americana, como o FMI (Fundo Monetário Internacional), o Banco Mundial e o Departamento do Tesouro dos Estados Unidos. Podemos dizer que o Consenso de Washington corresponde ao receituário econômico de caráter neoliberal, adotado mundialmente nos anos 1990, a partir da adesão de Pinochet (Chile) seguido por Margareth Thatcher (Inglaterra) e Ronald Reagan (EUA), seguido por uma legião de adesistas mercadológicos. 
Em 08 anos de governo, uma a uma as regras da política neoliberal decididas em Washington foram aplicadas e justificadas pelo ideal capitalista de desenvolvimento. São elas: a rigorosa disciplina fiscal, a redução dos gastos públicos, uma ampla reforma tributária (de acordo com as diretrizes do FMI), a utilização dos juros e do câmbio de mercado, a abertura comercial, o incentivo aos investimentos internacionais direto a partir da eliminação das restrições, o processo de privatização das empresas públicas, a flexibilização das leis econômicas e trabalhistas e, por último, o direito à propriedade intelectual. Temos, portanto, entre outras premissas, que a política neoliberal busca entregar o mercado a suas próprias regulamentações, sem que suponha a necessária intervenção política.

Para o nosso ensaio, o aspecto relevante desse retrospecto consiste no fato dele nos revelar que forma a proposta neoliberal explora a força de trabalho e a classe trabalhadora com vistas ao desenvolvimento das economias. Em suma, trata-se de um processo velado que entrega o trabalhador ao mercado controlado pelo capital, permitindo que eles sejam explorados sem limites, conforme explicam Nicolina Luiza de Petta e Eduardo Aparício Baez Ojeda (PETTA e OJEDA, 2003, p. 300):

A política neoliberal, apontada por Fernando Collor de Mello e Fernando Henrique Cardoso como caminho para a inclusão do Brasil no Primeiro Mundo, cobra dos trabalhadores de baixa renda um preço muito alto e faz a miséria crescer sensivelmente. Além disso, deixar setores essenciais como o de energia, abastecimento de água, telefonia e outros, nas mãos de empresas privadas pode se transformar em um problema sério para a população.

Ao aderir aos mandamentos do FMI e do Banco Mundial, FHC termina o seu mandato com o seguinte saldo: a recessão imperava, o trabalho fora precarizado até seu pior estágio, o desemprego atingia índices muito altos, o país se desindustrializava e os direitos sociais eram cada vez mais destruídos. Na opinião de Ricardo Antunes (ANTUNES, 2005, p. 38):

FHC foi servil para os de fora e truculento para os de baixo aqui de dentro, para lembrar a expressão de Florestan Fernandes. Desemprego em escala explosiva, que só em São Paulo chega a 
quase $20 \%$ da sua força de trabalho, precarização dos direitos (já bastante restritos) do trabalho num país que sempre cuidou bem do seu capital, desmontagem da previdência dos assalariados etc. Deslanchava, então, o processo de desregulamentação do trabalho, coerente com a flexibilização produtiva, a reengenharia, a lean production, este ideário e esta pragmática que quanto mais beneficia os capitais, mais destrói ou precariza os homens e mulheres que vivem do trabalho.

No contexto do Direito Laboral, observamos que a ideologia neoliberal provoca uma agressiva tendência flexibilizadora das relações de trabalho. Em razão disso, todo o ordenamento jurídico brasileiro passou a priorizar a negociação coletiva como amplo e efetivo processo de autocomposição dos interesses, para tornar possível o ajuste de cláusulas normativas entre empregado e empregador, destinadas a estabelecer regras nos contratos individuais de trabalho. Como exemplo dessa nova tendência, destacamos o teor da própria Constituição Federal que, já em 1988, apesar de trazer o princípio da irredutibilidade dos salários também permitiu exceções a essa regra, tendo em vista a ocorrência de acordo ou convenção coletiva nesse sentido (Art. $7^{\circ}$, VI).

Diversos outros exemplos de medida com objetivo de desregulamentação da relação de trabalho foram criadas pouco a pouco no Brasil, como exemplo destacamos o acréscimo do parágrafo único ao art. 422 da CLT, por força da promulgação da Lei nº 8.949/1994. Diante disso, o dispositivo legal passou a ter a seguinte redação: "Parágrafo único Qualquer que seja o ramo de atividade da sociedade cooperativa, não existe vínculo empregatício entre ela e seus associados, nem entre estes e os tomadores de serviços daquela”. Ainda no mesmo propósito, a criação pelo Tribunal Superior do Trabalho - TST, maior Corte de julgamentos do Direito do Trabalho no Brasil, da Súmula $\mathrm{n}^{\mathrm{o}} 331^{4}$, a aprovação da Lei $\mathrm{n}^{\mathrm{o}}$

\footnotetext{
${ }^{4}$ SÚMULA no 331 do TST - CONTRATO DE PRESTAÇÃO DE SERVIÇOS. LEGALIDADE

I - A contratação de trabalhadores por empresa interposta é ilegal, formando-se o vínculo diretamente com o tomador dos serviços, salvo no caso de trabalho temporário (Lei $\mathrm{n}^{\circ}$ 6.019, de 03.01.1974).

II - A contratação irregular de trabalhador, mediante empresa interposta, não gera vínculo de emprego com os órgãos da administração pública direta, indireta ou fundacional (art. 37, II, da CF/1988).
} 
9.601/1998, que dispõe sobre o contrato de trabalho a prazo determinado com a redução de encargos e obrigações trabalhistas às empresas, bem como a alteração do Art. 59, § $2^{\circ}$, da CLT, que passou a permitir a compensação quadrimestral/anual de horas trabalhadas além da jornada normal, quando antes se limitava à semana.

Em síntese, a tendência neoliberal a qual nos referimos age na desregulamentação do modelo fordista ${ }^{5}$, e o substitui por novas medidas que flexibilizam a produção e que criam novas formas de adequação da produção ao mercado. Cumpre, portanto, a nós nesse momento, aprofundar a caracterização de como se dão as relações de trabalho na fase do capitalismo que ainda vivenciamos, de modo que seja possível montarmos argumentos sólidos para responder ao questionamento posto.

De forma sucinta, a indústria de base no Brasil, assim como visto no mundo a partir da década de 1980, sofreu transformações com o crescimento das tecnologias de aprimoramento da produção, formada principalmente pela incorporação de máquinas automáticas e pelo desenvolvimento da robótica e da microeletrônica. Logo, ao passo em que se desenvolvem os fundamentos dos modos de produção também se modificam as relações de produção, uma vez que ambas são o sustentáculo para a produção do capital.

Casimiro Ferreira (FERREIRA, 2002) destaca três aspectos principais que torna possível analisar a descaracterização do paradigma clássico do

III - Não forma vínculo de emprego com o tomador a contratação de serviços de vigilância (Lei $n^{0}$ 7.102, de 20.06.1983) e de conservação e limpeza, bem como a de serviços especializados ligados à atividade-meio do tomador, desde que inexistente a pessoalidade e a subordinação direta.

IV - O inadimplemento das obrigações trabalhistas, por parte do empregador, implica a responsabilidade subsidiária do tomador dos serviços, quanto àquelas obrigações, inclusive quanto aos órgãos da administração direta, das autarquias, das fundações públicas, das empresas públicas e das sociedades de economia mista, desde que hajam participado da relação processual e constem também do título executivo judicial (art. 71 da Lei no 8.666, de 21.06.1993).

${ }^{5} \mathrm{O}$ modelo fordista corresponde ao processo de trabalho que predominou na formação do capitalismo, constituído pela produção em larga escala, linha de montagem e pelo controle das operações. Ricardo Antunes (ANTUNES, 2007, p. 25) acrescenta como elementos constitutivos a: “(...) separação entre elaboração e execução no processo de trabalho; pela existência de unidades fabris concentradas e verticalizadas e pela constituição/elaboração do operário-massa, do trabalhador coletivo fabril, entre outras dimensões”. 
direito do trabalho: a crise do emprego, a perda da dimensão coletiva e a precarização do contrato de trabalho. Sobre o primeiro aspecto o autor traz em seu texto dados da OIT (OIT, 1999) para demonstrar que no ano de 1998 um terço da força de trabalho mundial se encontrava desempregada ou ocupando subempregos. Desse contingente estão em maior número os jovens, os trabalhadores com pouca qualificação ou com idade avançada, as minorias étnicas, bem como as mulheres. A OIT estimou ainda que cerca de sessenta milhões de pessoas entre 15 e 24 anos procuram por trabalho. Conseqüência direta da diminuição de oportunidades de trabalho se reflete na falta de efetividade das normas de direito do trabalho básicas. Por exemplo, o trabalho infantil, repudiado pela OIT desde a elaboração da Convenção $\mathrm{n}^{\circ} 138^{6}$, de 06 de junho de 1973, recentemente atingiu marcas entre os duzentos e quatrocentos milhões de crianças de 5 a 14 anos com atividades econômicas em todo o mundo.

A crise do trabalho traz como conseqüência ainda a diminuição do número de pessoas assalariadas pertencentes à classe operária e o aumento do número de pessoas atuantes no setor de serviços. O sociólogo Antunes (ANTUNES, 2007) revela que na França, de 1975 a 1989 houve redução do número de operários pertencentes a população ativa de 39\% para 29,6\%, enquanto que na Itália os dados mostram redução de 40\% em 1980 para 30\% em 1990.

Sobre o tema, conclui Casimiro Ferreira: (FERREIRA, 2002, p. 272/273):

\footnotetext{
${ }^{6}$ Dispõe o art. $2^{\circ}$ da Convenção n ${ }^{\circ} 138$ da OIT:

1. Todo Estado-membro que ratificar esta Convenção especificará, em declaração anexa à sua ratificação, uma idade mínima para admissão a emprego ou trabalho em seu território e em meios de transporte registrados em seu território; ressalvado o disposto nos artigos $4^{\circ}$ a $8^{\circ}$ desta Convenção, nenhuma pessoa com idade inferior a essa idade será admitida a emprego ou trabalho em qualquer ocupação.

2. Todo Estado-membro que ratificar esta Convenção poderá posteriormente notificar o Diretor-Geral da Secretaria Internacional do Trabalho, por declarações ulteriores, que estabelece uma idade mínima superior à anteriormente definida.

3. A idade mínima fixada nos termos do parágrafo $1^{\circ}$ deste artigo não será inferior à idade de conclusão da escolaridade compulsória ou, em qualquer hipótese, não inferior a 15 anos. 4. Não obstante o disposto no parágrafo $3^{\circ}$ deste artigo, o Estado-membro, cuja economia e condições do ensino não estiverem suficientemente desenvolvidas, poderá, após consulta com as organizações de empregadores e de trabalhadores interessadas, se as houver, definir, inicialmente, uma idade mínima de 14 anos.
} 
(...) $\mathrm{Na}$ atualidade vivemos um período em que a função produtiva do trabalho permanece fundamental. No entanto, a questionar a importância do trabalho assalariado estão as formas de auto-emprego e de trabalho independente. Por essa via se transforma a função produtiva do trabalho assalariado, mas não a função produtiva do trabalho. Em qualquer dos casos, as transformações na função produtiva do trabalho problematizam o alcance e as fronteiras típicas do direito do trabalho. A função de distribuição é posta em causa pelos elevados índices de desemprego e pela precarização do emprego existente, estando cada vez mais dependente das "exigências" de competitividade e das "normas de regulação" que procuram indexar a evolução dos rendimentos e salários à evolução da produtividade. A fragmentação da função distributiva através do salário ou dos mecanismos de proteção social tem como conseqüência o bloqueio desta função como fonte de acesso ao direito do trabalho e ao direito social.

No que tange ao segundo aspecto de descaracterização do paradigma tradicional do trabalho temos a perda da dimensão coletiva do trabalho, segundo o qual destacamos a utilização de políticas gestacionais de pessoas no ambiente de trabalho e a descoletivização do trabalho industrial. São duas contradições basilares que merecem destaque. Sobre o primeiro tema presenciamos hoje um exacerbado conjunto de medidas individualizantes, baseados em processos de seletividade dos empregados. Toda grande empresa atualmente se empenha em distribuir prêmios de produtividade, prêmios pela assiduidade além de outros benefícios que visam desmantelar a consciência coletiva dos trabalhadores. Outro fator a influenciar essa perspectiva individualizante está no fato das empresas multinacionais dividirem a produção dos bens de consumo por diversos países do mundo, com objetivo de reduzir a remuneração paga pela força de trabalho nos países emergentes, além de conquistar a inserção em novos mercados. Ou seja, torna-se comum as grandes empresas manterem fábricas pelos diversos continentes do globo (células produtivas), e não mais apenas no país sede, de modo que, em função disso e consequentemente, a organização sindical também se dividiu perdendo força para conquistar benefícios que permitam atingir todos os trabalhadores.

Ainda é o estudo de Antunes (ANTUNES, 2007) que nos alerta para o fato dos sindicatos de trabalhadores não conseguirem reagir 
proporcionalmente à força dos movimentos do capital. Na visão do autor, os sindicatos estão em posição fixa de defesa, ou seja, perderam o espírito combativo, de enfrentamento e de reivindicação. No passado os sindicatos lutavam pelo controle social da produção, hoje, por outro lado, só se apresentam para negociar em processos coletivos que acentuam a exploração ditada pelo mercado. Conclui este autor (ANTUNES, 2007. p. 43/44): “(...) as diversas formas de resistência de classe encontram barreiras na ausência de direções dotadas de uma consciência para além do capital”.

Como última das caracterizações a evidenciar as mudanças ocorridas na esfera das relações de trabalho da atualidade, percebemos a intensificação das medidas de precarização do contrato típico pactuado entre empregador e empregado, com a expansão das modalidades de contrato por tempo parcial ou temporário, subcontratação e a famigerada terceirização. Inegável que medidas como estas são usadas para camuflar a entidade empregadora, fazendo cair por terra uma das características mais típicas da relação tradicional, qual seja, a figura do espaço de produção. Casimiro Ferreira (FERREIRA, 2002) entende que as novas formas de contratação de trabalhadores representam a decomposição do direito laboral, principalmente em razão da quebra das convenções típicas ligadas ao contrato de trabalho, pois se pensarmos que a regulação jurídica das relações de trabalho foram montadas tomando por base o trabalho subordinado assalariado e típico, a crise da tipicidade implica reconhecer que existe também uma crise das possibilidades reguladoras do próprio direito do trabalho.

Importante salientar, em contraposição, que a justificativa empresarial para utilização de novas modalidades comerciais e, certamente, novas formas de contratação corresponde, na opinião técnica, a uma estratégia de gestão frente às imposições do mercado competitivo globalizado. Conforme destaca Sebastião Nóbrega Pizarro (PIZARRO, 2010, p. 29), quando analisa 
que a figura do outsourcing ${ }^{7}$ pode trazer vantagens e desvantagens. Para o autor as maiores vantagens são a redução de custos fixos operacionais, a redução com a compra de equipamentos e, por decorrência disso, a menor necessidade de fornecimento (gasto). Para a classe trabalhadora, refere ainda que o recurso do outsourcing possa acarretar a precariedade de situação laboral, especificamente no que diz respeito a diminuição da remuneração, entretanto complementa: “diga-se que essa posição, nomeadamente no que ao despedimento por efeito da decisão de outsourcing concerne, pressupõe o integral respeito pelos direitos e garantias dos trabalhadores”.

Para os doutrinadores de direito do Trabalho a terceirização tem sido tema de muito debate e objeto de longos estudos. Apesar disso, não se observa uma variedade de opiniões acerca dos efeitos dessa modalidade de contratação, tanto que os pesquisadores diferenciam apenas quanto aos desajustes causados na relação tradicional de contratação do empregado. Godinho Delgado (DELGADO, 2008, p. 430), por exemplo, elabora um conceito técnico de terceirização e alerta ao final:

Para o Direito do Trabalho terceirização é o fenômeno pelo qual se dissocia a relação econômica do trabalho da relação justrabalhista que lhe seria correspondente. Por tal fenômeno insere-se o trabalhador no processo produtivo do tomador de serviços sem que se entendam a estes os laços justrabalhistas, que se preservam fixados com uma entidade interveniente. A terceirização provoca uma relação trilateral em face da contratação de força de trabalho no mercado capitalista: o obreiro, prestador de serviços, que realiza suas atividades materiais e intelectuais junto à empresa tomadora de serviços; a empresa terceirizante, que contrata este obreiro, firmando com ele os vínculos jurídicos trabalhistas pertinentes; a empresa tomadora de serviços, que recebe a prestação de labor, mas não assume a posição clássica de empregadora desse trabalhador envolvido.

O modelo trilateral de relação socieconomica e jurídica que surge com o processo terceirizante é francamente distinto do clássico modelo empregatício, que se funda em relação de caráter essencialmente bilateral. Essa dissociação entre relação econômica de trabalho (firmada com a empresa tomadora) e

\footnotetext{
${ }^{7}$ Sebastião Nóbrega Pizarro (PIZARRO, 2010) utiliza o termo outsoucing para se referir, genericamente, a estratégia empresarial que transfere serviços executados in-house para outra pessoa, mediante o pagamento pelo serviço prestado.
} 
relação jurídica empregatícia (firmada com a empresa terceirizante) traz graves desajustes em contraponto aos clássicos objetivos tutelares e redistributivos que sempre caracterizaram o Direito do Trabalho ao longo de sua história.

Outros autores são mais críticos, como observa o Juiz do Trabalho Souto Maior (MAIOR, 2008, p. 145):

(...) a terceirização tem contribuído para dificultar, na prática, a identificação do real empregador daquele que procura a Justiça para resgatar um pouco da dignidade perdida ao perceber que prestou serviço e não sabe sequer de quem cobrar seus direitos. A Justiça do Trabalho que tradicionalmente já se podia identificar do ex-empregado, dada a razoável incidência desta situação, passou a ser a Justiça do 'ex-empregado de alguém, só não se sabe quem’.

Na mesma linha de raciocínio, a Des. Ana Maria Vasconcellos (VASCONCELLOS, 2004, p. 702) entende que a flexibilização dos direitos trabalhistas não pode ser considerada como remédio para combater os males do mundo econômico. Conforme revela a jurista, algumas cifras significativas podem ser citadas para ilustrar sua opinião:

Na Espanha, a flexibilização iniciou-se em 1984, quando a taxa de desemprego era de $10 \%$, e, após 10 anos de reformas, o desemprego subiu para 20\%. Na Argentina, as reformas flexibilizadoras tiveram início em 1991, com uma taxa de desemprego de $6 \%$, que aumentou vertiginosamente até 1997 , atingindo 20\%. Após a reforma trabalhista no Chile, o desemprego aumentou até $20 \%$, e só diminuiu quando foram adotadas medidas drásticas, totalmente alheias ao trabalho, atingindo então a taxa de $7 \%$.

Ulrich Beck (BECK, 2008) na sua obra "Un nuevo mundo feliz - La precaridad del trabajo em la era de la globalización” inicia a análise da economia política e da insegurança com a afirmação de que observamos mundialmente o fenômeno da "brasileñización de occidente”. Para o autor no Brasil observa-se nitidamente a existência de trabalhos precários, a abundância de vendedores ambulantes, de pequenos comerciantes e artesãos, pessoas que se oferecem como assistentes domésticos e os nômades laborais, ou seja, a massa de trabalhadores que não possuem atividade profissional fixa. Na seqüência, diz o teórico que a situação de 
desregulamentação das relações trabalhistas tem começado a atingir também os países centrais da Europa, notadamente a Alemanha, sendo urgente, portanto, o estudo da economia política do risco por ele desenvolvido na obra, a partir de suas conseqüências contraditórias para a economia, política e sociedade. Beck (BECK, 2000, p. 10) continua o raciocínio ao elaborar cinco teses para compreensão da economia política do risco:

1. En la economía política de la inseguridad, el nuevo juego (y declive) del poder de expresa entre unos agentes vinculados a un territorio (gobiernos, parlamentos, sindicatos) y unos agentes económicos desvinculados de todo territorio (el capital, las finanzas y el comercio).

2. En esto se basa la impresión de que el margen de maniobra de los Estados se reduce al dilema de o bien <<pagar $>>$ la creciente pobreza con un mayor índice de paro (como ocurre en la mayoría de los países europeos) o bien tolerar un índice escandaloso de pobreza a cambio de algo menos de paro (como ocurre en EE.UU.).

3. Esto está relacionado con el hecho de que la sociedad laboral se acerca a su fin a medida que las personas son substituidas por tecnologías inteligentes. La creciente tasa de paro no se puede seguir achacando a crisis económicas cíclicas, sino a los éxitos de un capitalismo tecnológicamente avanzado. Esto significa también que ha fracasado el viejo instrumental económicopolítico y que todo trabajo remunerado se ve amenazado por el miedo a la sustituibilidad.

4. La economía política de la inseguridad describe con ello un efecto dominó. Lo que en los buenos tiempos se complementaba y reforzaba de manera recíproca (pleno empleo, pensiones más seguras, elevados ingresos fiscales, márgenes de maniobra de la política estatal) se ve ahora en recíproco peligro: el trabajo se torna precario; los cimientos del Estado asistencial se vienen abajo; las biografías personales se tornan frágiles; la pobreza de la vejez se programa anticipadamente; de las arcas vacías municipales no se puede sacar dinero para financiar el volumen cada vez más hinchado de la asistencia pública.

5. Por su parte, las estrategias ortodoxas pasan a la defensiva. Por doquier de reclama $<<$ flexibilidad $>>$, o, con otras palabras, que los empresarios puedan despedir más fácilmente a sus trabajadores. $<<$ flexibilidad $>>$ significa también que el Estado y la economía traspasan los riesgos e los individuos. Los contratos actuales con en su mayoría de corta duración y más fácilmente rescindibles: <<confórmate, pues tus conocimientos y diplomas ya no sirven, y nadie te puede decir lo que tienes que aprender para poder ser útil en el futuro $>>$. 
Como se observa, a terceirização representa uma grande mudança na relação de contratação entre empregado e empregador. De fato, esse fenômeno faz parte de um cenário maior e mais profundo relativo às novas formas de contratação, cuja realidade Antunes se atenta em descrever em sua obra. Segundo o autor (ANTUNES, 2007) são números correspondentes ao emprego e salário precários, bem como a regressão dos direitos sociais do trabalhador a redução de 501 mil empregos por tempo completo havida na França, de 1982 a 1988, e o aumento de 111 mil empregos por tempo parcial no mesmo período. Complementa, de 35 a 50\% da população trabalhadora britânica, francesa, alemã e norte-americana está desempregada ou desenvolvendo trabalhos precários/parciais. Nessa esteira, escreve o autor, citando Lojkine (ANTUNES, 2007. ps. 58/60), que da classe trabalhadora o capitalismo neoliberal tem exigido uma qualificação para as novas tecnologias, ao passo que ao mesmo tempo disponibiliza outros postos, cada vez em maior número, de natureza desqualificada. Explica:

Há, portanto, mutações no universo da classe trabalhadora, que varia de ramo para ramo, de setor para setor etc. desqualificouse em vários ramos, diminuiu em outros, como no mineiro, metalúrgico e construção naval, praticamente desapareceu em setores que foram inteiramente informatizados, como nos gráficos, e requalificou-se em outros, como na siderurgia, onde se pode presenciar a "formação de um segmento particular de 'operários técnicos' de alta responsabilidade, portadores de características profissionais e referências culturais sensivelmente diversas do restante do pessoal operário. Eles se encontram, ao nível de altos-fornos, aciaria, vaza contínua (...)

Observa-se o fenômeno similar na indústria automobilística, com a criação dos 'coordenadores técnicos' encarregados de assegurar os reparos e a manutenção de instalações altamente automatizadas, assistidos por profissionais de nível inferior e de especialidades diferentes”.

O cenário que rapidamente descrevemos tem sido chamado por teóricos das diversas áreas das ciências humanas como tempos de "crise do trabalho”. Os aspectos de mudanças nas relações de trabalho que destacamos em três pontos correspondem a formas encontradas pelo capital de reestruturar o seu modo de produção, uma vez que este foi abalado após a crise econômica de década de 1970. Como conseqüência da crise a classe 
operária tem sido prejudicada em seus direitos e garantias pelas medidas novas adotadas no mundo do trabalho que promovem a desregulação e a flexibilização da relação laboral. Não obstante, o fim dos projetos políticos existidos no Leste Europeu, que tentavam alcançar o socialismo, provocou um abatimento no movimento operário de todo o mundo, principalmente pela visão que se estabeleceu após o evento de que a queda da União Soviética significava a queda do socialismo e das idéias de Marx. Conforme nos lembra o educador Aparecido Nunes (NUNES, 2006, p. 107): “A queda do muro de Berlim, ocorrida em 1989, produziu um consenso ideológico que falsamente afirmava a derrota histórica do socialismo e a suposta vitória do capitalismo ocidental. Esse fato provocou um fortalecimento dos ideais capitalistas e da economia de mercado". Em suma, a crise do trabalho corresponde a um fenômeno social que atinge não só as relações de trabalho no capitalismo neoliberal, mas também o ideal político da classe trabalhadora.

A lógica das relações de trabalho que se pretende estabelecer atualmente é aquela que valoriza apenas o capital, de modo que o trabalho se torna apenas o seu meio de reprodução. Por conseqüência, a proposta do capitalismo global visa a reconstituição da hegemonia dos mercados em face dos Estados e o bloqueio das questões sociais e emancipatórias. Da mesma forma as relações laborais institucionalizadas sofrem os "ataques" dessa lógica, que promove a desregulamentação do direito do trabalho e a precarização das condições contratuais dos trabalhadores. Em nossos dias, Schaff (SCHAFF, 1984, p. 134) aponta para a trágica dicotomia que paira sobre a realidade desumana da globalização subserviente:

O mundo rico está orientado para o consumo e perdeu o sentido do esforço e da solidariedade, pois em poder de $20 \%$ dos homens estão concentrados $80 \%$ das riquezas. Se a hegemonia desmedida do Estado restringe a liberdade, não podemos ignorar que a hegemonia indiscriminada do mercado pode nos levar a um ponto de não retorno.

No Brasil, o direito do trabalho sofre as mudanças assim como observado na prática das relações neoliberais, ocorre, porém, que ela se dá 
pela forma própria do capitalismo, ou seja, de forma contraditória. Hodiernamente prevalece ainda o mesmo discurso, entretanto cada vez mais radical e agressivo, de atuação mínima do Estado, do custo Brasil, bem como da afirmação e ampla atuação do mercado como fonte reguladora das relações políticas e econômicas, com reflexos em toda a legislação laboral nacional. Nesse diapasão, os limites de atuação das normas jurídicas são ditados pela globalização neoliberal, em escandaloso ataque aos direitos sociais dos trabalhadores.

Experiências e práticas, no entanto, de resistência e de busca por melhores condições de trabalho não deixam de vistas no cenário da economia neoliberal que descrevemos. Já referimos que a OIT criou no ano de 1998 o programa de Trabalho Decente com objetivos e estratégias específicas para redução da pobreza mundial. Composto de quatro fatores (promoção dos direitos fundamentais do trabalho; emprego; proteção social e diálogo social) pretende-se com o programa fomentar o debate sobre relações de trabalho com objetivo transformar as oportunidades de emprego em oportunidades produtivas, bem como o modo de ingresso um processo mais justo. Ademais, o programa volta ações para desenvolver melhores condições de segurança aos trabalhadores e conseqüente proteção social para as famílias. Entende a Organização, que somente dessa forma seja possível garantir o direito fundamental ao trabalho, em condições dignas, de modo que isso possa levar o indivíduo a um desenvolvimento pessoal, com integração social, liberdade de expressão e organização, possibilidade de participação nas decisões e igualdade de trato entre homens e mulheres.

Uma ferramenta de atuação usada pela OIT na execução do programa consiste no mapeamento de regiões com déficit de trabalho decente, caracterizadas por locais onde se observa a exclusão social por decorrência do desemprego e do sub-emprego, dos trabalhos de pouca qualidade e improdutivos, das situações que oferecem perigos e prejuízos aos trabalhadores, dos direitos negados, da discriminação de todas as formas, do tratamento desumano de imigrantes, da falta de representação e voz, da 
concessão de proteção e solidariedade inadequadas para enfrentar enfermidades, incapacidades e a velhice.

O desafio que a OIT enfrenta para concretização do programa está nos riscos de agravamento da crise do trabalho contemporânea. Na leitura do programa percebe-se nitidamente o entendimento da OIT de que se uma ação concreta não for tomada o mundo caminhará para a fragmentação, para o protecionismo exacerbado e para conflito. O argumento escolhido para justificar essa tese é que uma escassez prolongada de oportunidades de trabalho decente e baixo consumo causam a quebra do contrato social existente nas sociedades democratas que pretendem o progresso. Por fim, acusa a OIT que experiências mundiais em diversos países revelaram o seguinte quadro: local onde a oportunidade de trabalho decente é ignorada observa-se elevação no risco de desordem, por outro lado locais que se comprometem a criar tais oportunidades o tempo para superação de crise é menor.

Em resumo, retiramos das orientações políticas do programa para um trabalho decente da OIT que cabe aos Estados integrar os objetivos econômicos e sociais com uma perspectiva de proteção do trabalho produtivo e executado em condições de dignidade. Para isso é proposto para os Estados ${ }^{8}$ :

Crecimiento, inversiones y desarrollo empresarial son claramente necesarios. La promoción de un ambiente favorable y competitivo para la iniciativa privada, que abarca desde la ayuda a las personas a organizarse para salir de manera progresiva de la economía informal hasta la mejor manera de coordinar los intereses nacionales con las inversiones extranjeras, es clave para el futuro del trabajo.

Tudo o que foi exposto é fundamental para entendermos com quais objetivos o Brasil elaborou as 14 ações programáticas no novo PNDH-3. Parece-nos claro, a partir de agora, que o objetivo estratégico número VI -

\footnotetext{
8 cf. "Hacer del trabajo decente un objetivo global”. Texto on-line. Disponível em: http://www.ilo.org/global/about_the_ILO/Media_and_public_information/Feature_stories/lang-es/WCMS_071261/index.htm. Acessado em junho de 2010.
} 
Garantia do trabalho decente, adequadamente remunerado, exercido em condições de igualdade e segurança - reforça a agenda do programa de trabalho decente da OIT, como ação prática a nível nacional. Contudo, descrevemos anteriormente que a crise do trabalho é algo complexo com implicações econômicas, políticas, sociais e culturais de âmbito universal. A OIT, como maior órgão internacional de defesa dos direitos dos trabalhadores, a partir do programa para trabalho decente significa uma instância de defesa e de orientação política fundamentais para trabalhadores e trabalhadoras de todo o mundo, sendo o PNDH-3 uma prova de sua influencia. Ocorre que o cenário de globalização neoliberal que vivemos atua em esferas que vão além do que pretende a OIT, ela cria uma lógica difícil de ser combatida com ações programáticas.

Nessa esteira, compartilhamos do entendimento do sociólogo português Casimiro Ferreira (FERREIRA, 2002) quando diz que a possibilidade de ruptura da crise do trabalho só acontecerá com o reconhecimento de dois pressupostos básicos. O primeiro já está amplamente apresentado na formulação de trabalho decente levada a cabo pela OIT, a segunda, mais emergente, corresponde a uma proposta do também sociólogo português Boaventura de Sousa Santos, denominada descoberta das potencialidades democráticas do trabalho pela cidadania. Isso, no nosso entendimento, só será possível com uma radical mudança na esfera econômica de nossa sociedade, em outras palavras, com a superação do capitalismo.

Em sua contribuição para uma concepção decente e democrática do trabalho e dos seus direitos, elabora o mesmo autor três estratégias para realização dos dois pressupostos básicos mencionados. A primeira diz respeito à criação de padrões mínimos de qualidade para que os produtos possam circular livremente no mercado mundial (FERREIRA, 2002). Tratase de garantir o respeito a direitos fundamentais dos trabalhadores como também entender a proteção as condições de trabalho, composta no entender desse autor como condições de segurança, saúde e higiene, formação profissional e aprendizagem, horários de ativação, acesso a formas 
democráticas de resolução de conflitos e salários mínimos que atendam necessidades mínimas.

Como segunda estratégia de realização de um trabalho decente e democrático, alerta o autor que torna-se urgente garantir segurança na representação e proteção da chamada “voz sindical”. De fato, e economia neoliberal que destacamos visa justamente desmantelar essas duas esferas trabalhista, sendo a crise do trabalho que descrevemos o reflexo disto. Cabe, portanto aos trabalhadores lutar por esferas de participação, por condições de negociação e pela implementação de uma agenda reivindicativa. Resume Casimiro Ferreira (FERREIRA, 2002, p. 291): “O reforço do diálogo social ancorado na capacidade e desejo de todos os parceiros nele participarem de forma responsável e numa base de equidade pode ter um papel decisivo na 'governação' ou regulação das relações de trabalho à escala global”.

Por último, discorre Casimiro Ferreira sobre a transformação dos sistemas de relações laborais e da sua conseqüente regulação jurídica. Para o autor novas relações sociais, econômicas e políticas deveriam ser acompanhadas de novas formas de garantir segurança ao trabalho. Aqui reside, sem dúvidas, a maior questão para a conquista de um trabalho decente e democrático. Na opinião do autor:

(...) perante o cenário de crise e de transformação por que passam o direito do trabalho e as relações laborais, "uma das tarefas centrais da nova teoria democrática consiste na politização do espaço de produção" (Santos, 1994: 235). Tarefa tanto mais necessária quanto se sabe que o problema da democraticidade nos locais de trabalho é em muitos sentidos paradigmático dos problemas da política e da democracia em geral.

Diante do que foi apresentado, como responder ao questionamento central: como garantir a defesa dos direitos humanos dos trabalhadores brasileiros, tendo em vista a formação de uma nova ordem econômica? O novo PNDH-3, a nosso ver, assume um papel particular para essa perspectiva, na medida em que coaduna com a atuação institucional da OIT para garantia de um trabalho decente. Não obstante, indicamos as potencialidades do direito do trabalho como instrumento de garantir os 
direitos humanos de cada trabalhador, desde que ele atenda aos anseios da sociedade que pretende superar as dominações históricas. Devemos associálo diretamente ao conhecimento e a prática, pois somente dessa forma exercitamos sua potencialidade emancipatória de produzir justiça social e equidade política. A legislação trabalhista, como fruto do processo legal, deve ser determinada pela ancoragem das lutas e potencialidades sociais e políticas, logo, se prevalecer no Brasil um ciclo de crescimento das forças dos movimentos sociais que almejam a distribuição de direitos haveremos de criar, definir, sustentar e acreditar numa expansão dos direitos trabalhistas e para os trabalhadores, por outro lado, se prevalecer a lógica de reprodução do capital defendida pelo neoliberalismo globalizante, teremos a manutenção das propostas de flexibilização que desagregam as classes trabalhadoras e que aviltam as suas condições laborais.

No vasto campo das relações de trabalho, as implicações neoliberais continuam promovendo o expurgo das normas legais de caráter rígido e que regulamentavam a relação tradicional de trabalho, ao passo em que faz surgir, em substituição, dispositivos desregulamentadores de direito do trabalho. Em síntese, as dimensões do capitalismo mundial atual revelam que os mandamentos neoliberais só fizeram piorar a condição de vida do trabalhador, pois instaurar-se-ia em todo o globo a chamada crise do emprego. Acompanhando a crise, relatamos que o neoliberalismo trouxe conseqüências como o aumento do número de desempregados, a descoletivização dos trabalhadores, bem como a precarização das condições de trabalho, notadamente observadas no aspecto singular das medidas de terceirização.

Não obstante, o momento de tensão que vive a sociedade brasileira, em especial a classe trabalhadora, pode e deve ser entendida como um momento potencial, conforme descreve Mészarós (MÉSZARÓS, 2007, p. 378/380):

O desafio e o fardo do tempo histórico não poderiam ser maiores do que nas circunstâncias atuais. Pois, os próprios riscos não poderiam ser maiores, no sentido de que o modo 
estabelecido de reprodução sócio-metabólica - cujas determinações estruturais instrumentais impedem que funcionem de outra maneira - agora ameaça diretamente a sobrevivência da humanidade.

\section{(...)}

O desafio e o fardo de tempo histórico são inseparáveis de nossa consciência da humanidade ameaçada.

Os anos 1980 e 1990 também foram as conjunturas temporais que destacaram e condensaram um novo e amplo processo cultural de participação popular, de uma diversificada eclosão de movimentos sociais e populares no Brasil, com destaque para os movimentos vanguardistas da defesa dos Direitos Humanos (1980), da luta pela terra e reforma agrária (MST, 1980-1990), das lutas pelas novas formas de defesa do meio ambiente (Eco 1992 e o Direito Ambiental brasileiro), as políticas de gênero (a questão da violência contra a mulher, a discriminação e violência racial, a discriminação e violência contra os grupos homoafetivos) que se integraram à defesa da Criança e do Adolescente, do Idoso, dos portadores de necessidades especiais, entre outros. Numa década e meia de enfrentamentos e lutas pela superação da ditadura militar uma geração nova de estudantes, cidadãos, grupos e movimentos sociais e populares lograram inscrever, na teia da história, a possibilidade de uma nova sociedade, uma orgânica e efetiva modernização institucional e jurídica, de modo a constituir um substrato ético revolucionário e superador de nossa identidade autoritária. Os anos 1980, a longa e penosa década neoliberal de 1990 e os desafiadores e promissores dos primeiros nove anos desse novo milênio já constituem suficiente temporalidade e historicidade para configurar uma nova marcha dos direitos humanos e sociais.

Um passo significativo e importante para a defesa dos direitos humanos foi dado com a criação do novo Plano de Direitos Humanos PNDH-3. Não nos restam dúvidas de que esse plano marca uma proposta nova na política brasileira, marcada sempre pelo conservadorismo e pelo distanciamento das causas sociais. Como dito anteriormente, o Plano é fruto de reivindicações de diversos movimentos sociais e corresponde, em muito, 
ao ideal de busca de uma sociedade democrática e de direitos. No que tange ao trabalho e ao direito do trabalho, o novo projeto pode ser entendido como uma ação que está em consonância com a concepção adotada pela OIT sobre trabalho decente, uma vez que essa é orientada na promoção dos direitos fundamentais do trabalho; na garantia de emprego; no fortalecimento da proteção social e na realização do diálogo social.

Nesse ponto elaboramos o argumento que busca responder à pergunta que destacávamos no início do texto: podemos extrair dessas ações programáticas aquilo que se entende por concepção decente e democrática do trabalho? Sob a ótica do que defende a OIT sobre trabalho decente a resposta nos parece positiva, ou seja, as ações programáticas do novo PNDH-3 prevêem sim medidas que buscam a promoção dos direitos fundamentais do trabalho, a criação de mais e melhores empregos, a proteção social do trabalho e o diálogo social. Desse ponto específico remetemos ao outro questionamento: até que ponto esse novo plano de Direitos Humanos contribui para a busca de um trabalho decente e para a criação de um direito laboral igualmente democrático? Para responder esta pergunta, nos apoiamos nos estudos de Casimiro Ferreira quando propõe as três estratégias para conquista do trabalho decente e democrático na sociedade globalizada neoliberal (exigência de padrões mínimos de qualidade para que os produtos possam circular livremente no mercado mundial, segurança na representação e proteção da “voz coletiva” e transformação do sistema de relações laborais e da normatividade laboral).

Concordamos com o autor e acreditamos ser a politização dos espaços de produção o grande desafio para que a sociedade brasileira possa alcançar os ideais emancipatórios propostos. Nesse sentido será preciso que continuemos com os processos de revitalização dos movimentos sociais populares, bem como a retomada das utopias em torno de um projeto de sociedade emancipatório.

Nesse diapasão, aplicamos os referenciais teóricos acima descritos para responder ao último questionamento: podemos afirmar que o Plano de 
Direitos Humanos brasileiro está em consonância com as conjunturas sociais, econômicas e políticas da sociedade capitalista globalizada, da qual se revela atualmente uma potencial transformação nas relações e no direito do trabalho? Com absoluta certeza, o PNDH-3 foi um avanço sem precedentes para o Brasil no que diz respeito à defesa dos direitos humanos dos trabalhadores. Salienta-se, no entanto, que o embate com interesses hegemônicos envolve não só o reconhecimento desses direitos na esfera normativa nacional, mas também o enfrentamento político e, principalmente, o uso do direito do trabalho como trincheira emancipatória.

A marcha dos setores organizados dos trabalhadores e a considerável expansão dos direitos sociais evidenciados nas duas últimas décadas nos permitem ter convicções de que as tendências históricas opressoras não permanecerão para sempre. Essa obra será resultado de um amplo processo de educação política e maximização do manejo dos direitos sociais e trabalhistas, no âmago dessas forças e tarefas sociais dormita a revolução, despida de validade dogmática, como uma original possibilidade histórica, intrinsecamente nova, politicamente democrática e eticamente humanizadora.

\section{Referências}

ANTUNES, R. Adeus ao Trabalho. Campinas. Ed. Cortez. 12a Ed. 2007.

A Desertificação Neoliberal no Brasil (Collor, FHC e Lula). Campinas-SP. Ed. Autores Associados. $2^{\text {a Ed. }} 2005$.

BECK. U. Un nuevo mundo feliz - La precariedad del trabajo en la era de la globalización. Barcelona. Ed. Paidós. 2000.

¿Qué es la globalización? Falacias del globalismo, respuestas a la globalización. Barcelona. Ed. Paidós. 1998.

CANOtilho, J. J. G. Direito Constitucional e Teoria da Constituição. Coimbra. Ed. Almedina, $7^{\text {a }}$ ed. 2003.

DELGADO, M. G. Curso de Direito do Trabalho. São Paulo. Ed. Ltr. $7^{\text {a }}$ ed. 2008. 
FERREIRA, A. C. Para uma Concepção Decente e Democrática do Trabalho e dos seus Direitos: (Re)pensar o direito das relações laborais. in SANTOS, B. S. (org). A Globalização e as Ciências Sociais. São Paulo. Ed. Cortez. 2002.

FILHO, M. G. F. Direitos Humanos Fundamentais. São Paulo. Ed. Saraiva. 10 Ed. 2008.

FURTADO, C. Formação Econômica do Brasil. São Paulo. Ed. Cia das Letras. $34^{\mathrm{a}}$ Ed. 2007.

MAIOR, J. L. S. Curso de direito do trabalho: a relação de emprego. São Paulo. Ed. Ltr. Volume II. 2008.

MÉSZÁROS, I. O Desafio e o Fardo do Tempo Histórico. São Paulo. Ed. Boitempo. 2007.

NUNES, C. A. Educar para a Emancipação. Campinas-SP. Ed. Sophos. 2006

PEREIRA, E. T. O OP (Orçamento Participativo) como processo de educação política: um estudo da histórica experiência de Várzea Paulista-SP. Tese de Doutorado - UNICAMP-Campinas. 2007, mimeo.

PETTA, N. L. de; OJEDA, E. A. B. História: Uma Abordagem Integrada. São Paulo. Ed. Moderna. $2^{\text {a }}$ Ed. 2003.

PRADO JÚNIOR, C. História Econômica do Brasil. São Paulo. Ed. Melhoramentos. 1945.

PIZARRO, S. N. O contrato de outsourcing. Coimbra. Coimbra Editora. $1^{\text {a }}$ Ed. 2010.

SANTOS, B. de S. Por uma concepção multicultural de direitos humanos, Revista Crítica de Ciências Sociais nº. 48, pg. 11-32, 1997.

. Os processos da globalização. In SANTOS, B. S. (org.)

Globalização: Fatalidade ou Utopia. Porto, Ed. Afrontamento, 2001.

SARLET, I. W. Eficácia dos Direitos Fundamentais. Porto Alegre, Ed. Livraria do Advogado. $2^{\mathrm{a}}$ Ed. 2001.

SCHAAFF, A. A Sociedade Informática. Rio de Janeiro, Ed. Guanabara. 1998.

VASCONCELLOS, A. M. Reflexões acerca do Regime de 12x36. São Paulo. Ltr. Suplementos Trabalhistas 151/04 - Ano 40. 2004. 